\title{
Characterization and Utilization of Starches Extracted from Florencia and Waxy Maize Hybrids for Tablet Formulation: Compaction Behaviour and Tablet Properties
}

\author{
Anikó Szepes1, Piroska Szabó-Révész², János Bajdik², Péter Kása Jr.², Miklós Neményi³, \\ Roland Pap ${ }^{3}$, Attila József Kovács ${ }^{3}$, Klára Pintye-Hódi2* \\ ${ }^{1}$ Martin Luther University Halle-Wittenberg, Center for Engineering, Thermal Process Technology, Halle (Saale), \\ Germany \\ ${ }^{2}$ Department of Pharmaceutical Technology, University of Szeged, Szeged, Hungary \\ ${ }^{3}$ Faculty for Agricultural and Food Sciences, Institut of Biosystems Engineering, University of West Hungary, \\ Mosonmagyaróvár, Hungary \\ Email: "klara.hodi@pharm.u-szeged.hu
}

Received 7 January 2014; revised 6 February 2014; accepted 26 February 2014

Copyright @ 2014 by authors and Scientific Research Publishing Inc.

This work is licensed under the Creative Commons Attribution International License (CC BY).

http://creativecommons.org/licenses/by/4.0/

(c) (9) Open Access

\section{Abstract}

The aim of this work is to analyze the particle characteristics, such as shape, roundness and size, of starches extracted from Florencia and waxy maize hybrids. The micromeritics and structural properties of the samples were examined. The evaluation of flow properties, densification and compression behaviour of the powders was carried out. Physical parameters and swelling characteristics of tablets containing Florencia and waxy maize starch were also studied. Starch samples were compared with respect to their applicability as excipients in tablet formulation. The samples exhibited identical structure and similar particle characteristics. Maize starch extracted from the Florencia dent hybrid showed better flowability and compressibility in tableting experiments, which resulted in better mechanical tablet properties. With regard to utilization as a disintegrant, Florencia starch indicated rapid and intensive swelling and proved to act more effectively in the swelling process than waxy maize starch.

\section{Keywords}

Maize Starch; Micromeritics; X-Ray Diffraction; Compression Behaviour; Tablets 


\section{Introduction}

Starch is a naturally-occurring biodegradable polymer which is widely used for different industrial utilizations. However, there is often a need to modify product properties for a particular application in order to satisfy market requirements [1]. Improvements in the properties of starches can be achieved by the chemical or physical modification of extracted starch. In addition, polymer characteristics can also be controlled genetically by manipulation of starch biosynthesis [2].

Structures of starch granules are described semi-crystalline containing altering crystalline and amorphous regions, in which the two principal components, amylose and amylopectin, are embedded [1] [3]-[7]. The big diversity of starch properties can be attributed to the difference in relative proportions of amylose and amylopectin in various starch species and the characteristics of these molecules [2]. For example, amylose content of maize starch strongly affects several physical, chemical and functional properties, such as pasting temperature, viscosity and gel stability and the degree of starch granules' susceptibility to enzymatic digestion [8].

The level of granule bound starch synthase (GBSS), which catalyses the amylose synthesis, is reduced in the waxy maize genotype. Hence, the synthesis of amlyose is partially or completely blocked at molecular level in waxy maize starch [2]. According to the literature, waxy maize starch is an appropriate candidate for the production of biodegradable plastics [9] [10]. Starch and its modifications play a prominent role in pharmaceutical formulations used as disintegrants, fillers, binders and gel/film-forming polymers [12]-[17]. Waxy starches largely composed of amylopectin have been reported to act more effectively in controlled drug release and mucoadhesive drug formulations than native starches [18]-[22] due to the fact that the intramolecular hydrogen bonds between the amylopectin chains stabilize the matrix structure of the tablet.

Florencia is a dent hybrid exhibiting high kernel yield and high efficiency in hydrolysis and fermentation processes. These favourable properties promote the application of this maize hybrid as renewable resource for bioethanol production [11]. Pharmaceutical applications of the Florencia genotype have not been reported in the literature so far.

The aim of this work is to characterize the morphology, physical properties and some pharmaceutical technological parameters of starches extracted from Florencia and waxy maize hybrids and to compare them with respect to their applicability as excipients in tablet formulation.

\section{Materials and Methods}

\subsection{Materials}

Starches were extracted from Florencia and waxy maize hybrids (National Starch and Chemical Ltd., Manchester, UK) in laboratory scale via the wet milling procedure by using a Quaker City laboratory disk mill (The Straub Co., Philadelphia, USA) [23].

\subsection{Morphological Study}

The particle morphology was investigated with a SEM (Hitachi $2400 \mathrm{~S}$, Hitachi Scientific Instruments Ltd., Tokyo, Japan). A polaron sputter coating apparatus (Bio-Rad SC502, VG Microtech Uckfield, UK) was applied to create electric conductivity on the surface of the samples. The air pressure was 1.3 - $13 \mathrm{mPa}$.

\subsection{Analysis of Particle Size and Particle Roundness}

Determination of particle size and particle roundness was carried out with a Laborlux S light microscope and a Qantimet 500MC (Q500MC) image processing and analysis system (LEICA Cambridge Ltd., UK). Roundness is a shape factor that provides information about the circularity of particles. It is calculated by software according to the following equation:

$$
\text { Roundness }=\frac{\text { Perimeter }^{2}}{4 \pi} \times \text { Area } \times 1.064
$$

The perimeter was calculated from the horizontal and vertical projections, with an allowance for the number of corners. An adjustment factor of 1.064 corrected the perimeter for the effect of the corners produced by digitization of the image. When roundness value approaches one, the particle morphology is regarded spherical 


\section{[24].}

\subsection{Micromorphological Studies}

The specific surface areas $\left(\mathrm{F}_{\mathrm{BET}}\right)$ and micropore volumes $(\mathrm{V})$ of the samples were determined with Micromeritics ASAP 2000 equipment (Instrument Corp., Norcross, GA, USA) from the data of nitrogen adsorption and desorption isotherms at the boiling point of liquid nitrogen under atmospheric pressure $\left(-196^{\circ} \mathrm{C}\right)$. The specific surface was calculated in the validity range of the BET (Brunauer, Emmett, Teller) isotherm from the slope and intercept of a line characterized by five measuring points [25]. The samples $(1.5-2.0 \mathrm{~g})$ were degassed at $60^{\circ} \mathrm{C}$ in a vacuum up to $1 \mathrm{~Pa}$ absolute pressure. After degassing, the samples were weighed again and the morphological parameters were calculated for the "surface-cleaned" masses of the samples. The micropore volumes were calculated via the BJH (Barrett, Joyner, Halenda) method [26]. The investigations were made in triplicate.

\subsection{X-Ray Diffraction}

The powder X-ray diffraction profiles were taken with an X-ray diffractometer (Philips PW 1050/70 PW 1710). The measurement conditions were as follows: radiation source: $\mathrm{CuK} \alpha$, scan speed: 0.052 theta $\cdot \mathrm{s}^{-1}$.

\subsection{Moisture Content}

Moisture content was determined by using the HR73 Halogen Moisture Analyzer (Mettler-Toledo GmbH, Greifensee, Switzerland). Approximately $4 \mathrm{~g}$ material was heated at $105^{\circ} \mathrm{C}$ and the change in mass was recorded with a precision of $0.1 \mathrm{mg}$.

\subsection{A Study of Flow Time, Bulk Density and Carr Index}

Flow time (s/100 ml) was measured with an ASTMD 329 - 38 equipment (according to Ph. Eur.).

Bulk densities (poured and tapped densities) were determined with a STAV 2003 Stampfvolumeter (Engelsmann A.G. Apparatebau, Ludwigshafen, Germany) [27]. An appropriate amount of the sample was gently added up to the $250 \mathrm{ml}$ mark in a $250 \mathrm{ml}$ tared graduated cylinder. The volume read directly from the cylinder was then used to calculate the poured density according to the relationship: mass/volume. For the tapped density, the cylinder was tapped 200 times. The volume of the sample was then read off and used in the calculation. The results were calculated from three parallel measurements.

True density was determined with a Quantachrome SPY-2 stereopycnometer (Quantachrome Corp., Syosset, New York, USA). The pycnometric density was calculated from the mass and the pycnometric volume. Results are averages of three replicate determinations.

The Carr index was calculated from the densities according to Equation (2) [28]:

$$
\text { Carr index }(\%)=\frac{\text { Tapped density }- \text { Poured density }}{\text { Tapped density }} \times 100
$$

The Carr index reflects the compactibility of the powders, and there is a correlation between the Carr index and the flowability of the particles [29]. A Carr index smaller than $15 \%$ is related to good flow characteristics, while a value above $25 \%$ indicates poor flowability.

\subsection{Compression Data Analysis}

The powder blend used for the examination of compression behaviour contained $20 \%$ starch, $78 \%$ microcrystalline cellulose as binder (Avicel PH $101^{\circledR}$, FMC Corp., Philadelphia, USA) and $1 \%$ magnesium stearate as lubricant, respectively.

Work calculation (input work ( $\left.E_{\text {input }}\right)$, effective work $\left(E_{2}\right)$, elastic work $\left(E_{3}\right)$, plasticity $\left(P l_{S-M}\right)$, Emschermann's index $(P l)$, compressibility $\left(P r_{\text {(mass) }}\right)$ and friction parameters such as lubrication ratio $(R)$ and friction work $(F W)$ were determined from the force-displacement and force-time data recorded during the compression cycle [13]. Elastic recoveries $(E R)$, which characterize the relaxation of the compact, were expressed as percent increase in tablet thickness measured directly after ejection and $24 \mathrm{~h}$ later, respectively.

Plasticity $\left(\mathrm{Pl}_{S-M}\right)$ was determined according to Stamm-Mathis using the following equation [30]: 


$$
P l_{S-M}(\%)=\frac{E_{2}}{E_{2}+E_{3}} \times 100
$$

Where $E_{2}$ is the deformation work which includes the useful works invested in deformation and the friction during processing and $E_{3}$ is the degree of elastic recovery during processing.

$E_{2}$ and $E_{3}$ can be calculated from the force-displacement curve. A plasticity value near 100 refers to plastic deformation during compression [31].

The Emschermann's plasticity $\left(P l_{E}\right)$ is the ratio of elastic $(B)$ and plastic $(A)$ deformation (4). The A and B values are calculated from the force-time curve [32].

$$
P l=\frac{B}{A}
$$

Compressibility $\left[\operatorname{Pr}_{\text {(mass) }}\right]$ was calculated via the following equation:

$$
P r_{\text {mass }}=\frac{\sigma_{x}}{W_{\text {spec }}}=\frac{\sigma_{x}}{E_{2} / \mathrm{m}}\left(\frac{P a}{\mathrm{~J} \cdot \mathrm{kg}^{-1}}\right)
$$

Where $\sigma_{x}$ is the tensile strength, $W_{\text {spec }}$ the expresses effective work $\left(E_{2}\right)$ invested into the compression of the unit mass of substance $(m)$ at a given compression force.

The lubrication ratio $(R)$, i.e., the ratio of the lower punch force $\left(F_{l p}\right)$ to the upper punch force $\left(F_{u p}\right)$ at maximum pressure [33]:

$$
R=\frac{F_{l p}}{F_{u p}}
$$

An $R$ value higher than 0.81 indicates appropriate lubrication during compression.

Elastic recovery (ER) was calculated according to Armstrong and Haines-Nutt [34]:

$$
E R(\%)=\left[\frac{\left(t_{2}-t_{1}\right)}{t_{1}}\right] \times 100
$$

where $t_{1}$ is the minimal thickness of the powder bed in the die and $t_{2}$ is the thickness of the recovered tablet.

\subsection{Tablet Preparation}

Tablets were produced with an instrumented eccentric tableting machine (Korsch EK0, Berlin, Germany) equipped with strain gauges and a displacement transducer for the upper punch by using three different compression forces (20 $\pm 2 \mathrm{kN}, 10 \pm 2 \mathrm{kN}, 5 \pm 1 \mathrm{kN}$ ) at an air temperature of $24^{\circ} \mathrm{C}$ and an air relative humidity of $39 \%$. The rate of compression was 30 tablets/min.

The composition of the tablets was as follows: Starch $60 \mathrm{~g}$, magnesium stearate $3 \mathrm{~g}$ and Avicel PH $101^{\circledR}$ (FMC Corp., Philadelphia, USA) or Parmcompress ${ }^{\circledR}$ (G. Parmentier, Frankfurt, Germany) $237 \mathrm{~g}$ for 1000 tablets. The components were mixed for 10 minutes with a Turbula mixer (Willy A. Bachofen, Maschinenfabrik, Basel, Switzerland) at $50 \mathrm{rpm}$.

The compression tools were single, flat punches $10 \mathrm{~mm}$ in diameter, furnished with strain gauges and a displacement transducer. The strain gauges allow the pressure forces on the upper and the lower punches to be followed with force-measuring equipment, which was calibrated with a WAZAU HM-HN-30 kN-D cell (Kaliber, Budapest, Hungary). The displacement transducer was fitted over the upper punch. The transducer distance accuracy was checked by using five measuring pieces of different thicknesses (2.0, 5.0, 7.5, 10.0 and $15.0 \mathrm{~mm})$ under zero load (Mitutoyo, Tokyo, Japan).

\subsection{Tablet Characterization}

Thickness and diameter of the tablets were measured with an electronic digital micrometer (Mitutoyo OP 1-HS, Tokio, Japan) immediately after ejection and after $24 \mathrm{~h}$. The diametral crushing force of the compacts was measured $24 \mathrm{~h}$ after ejection with the Heberlein equipment (Heberlein and Co. AG, Zürich, Switzerland). 


\subsection{Examination of Swelling Characteristics}

The equipment and the software used to study the swelling characteristics of the tablets were developed in our institute [35].

The tablets containing Parmcompress ${ }^{\circledR}$ were placed on a perforated sample holder $10 \mathrm{~mm}$ in diameter. $5 \mathrm{ml}$ deionised water was added at room temperature, which initiated swelling of the polymers upon contact with the comprimates. The generated swelling force is transmitted vertically to the microbalance and converted to an electrical sign evaluated by the software.

The non-linear regression of the Weibull equation was used to calculate the characteristic swelling time $\left(\mathrm{t}_{63.2 \%}\right)$, during which $62.3 \%$ of the maximal swelling passes off [36]:

$$
\frac{M}{M_{0}}=1-\exp \left\{-\left[\frac{t-T}{a}\right]^{\beta}\right\}
$$

where $M$ is the swelling force generated at time $t, M_{0}$ is the maximal swelling force, $T$ is the lag time, $\beta$ is a shape parameter and $a$ is a time parameter of the swelling curve.

\subsection{Statistical Analysis}

Statistical analysis was performed using ANOVA test and differences were considered statistically significant for $\mathrm{p}$ values $<0.05$.

\section{Results and Discussion}

The starch samples contained non-agglomerated particles irregular and polyhedral in shape (Figures 1(a), (b)). However, as shown in Figures 1(c) and 1(d), some spherical/oval starch granules could be also observed. The SEM micrographs depict some particles with extended surface damage (Figures 1(e), (f)), which can be related to the mechanical process applied for the isolation of starch granules (wet milling).

The particles of both samples exhibit monodisperse size distribution with a geometric mean particle size of 10 $20 \mu \mathrm{m}$ (Figure 2). Considering particle roundness, 50\% of the waxy maize starch particles fall into the range of 1 - 1.1, while the majority of the granules extracted from the Florencia hybrid posses a roundness value of 1.1 1.2 (Figure 3). A considerable bigger amount of the Florencia particles displays a roundness higher than 1.2.

No significant difference was found between the specific surface areas $\left(\mathrm{F}_{\mathrm{BET}}\right)$ of the starches (Table 1$)$, which is related to the equal particle size and similar particle morphology of the samples. However, pore volume (V) and pore diameter (D) data included in Table 1 indicate considerable differences in micromeritics. The pore size varies in a wide range $(1.7-100 \mathrm{~nm})$ including meso- $(2-50 \mathrm{~nm})$ and macropores $(>50 \mathrm{~nm})$, respectively (Figure 4). The higher average pore volume of waxy maize starch is reflected by the large slope of the cumulative pore volume-size distribution curve of the sample. The exact volume ratios of the pores given in Figure 4 quantitatively characterize the microstructure of the samples and reveal that the micromeritics of waxy maize starch are mainly determined by the mesopores, while meso- and macropores have an equal impact on the micromorphology of the Florencia genotype. The different ratios of meso- and macropores in the samples compensate the differences is average pore volume and pore diameter resulting in similar specific surface areas.

The X-ray diffraction curves of the starch samples are presented in Figure 5. Both samples show an A-type $X$-ray pattern obtained for cereal starches, with strong reflections at about $15^{\circ}$ and $23^{\circ} 2 \theta$, and an unresolved doublet at $17^{\circ}$ and $18^{\circ} 2 \theta$ [7]. The X-ray study did not reveal any structural differences between the starch genotypes.

Both the bulk and true densities of waxy maize starch were found significantly higher than those obtained for the Florencia hybrid (Table 2). The same tendency was observed for the angle of repose and the Carr index. A Carr index higher than $25 \%$ indicates poor flowability which was confirmed by the measurements of flow time: The samples did not display free flow. These results can be attributed to the strong attractive forces acting between the starch particles. The cohesive powder flow is a consequence of the relatively small particle size, which provides high surface areas promoting interparticle attraction.

The compression properties and densification behaviour of the starches were evaluated from the plot of the compression force-displacement and force-time data, respectively. This kind of examination is a part of the preformulation studies during the development of solid dosage forms. 


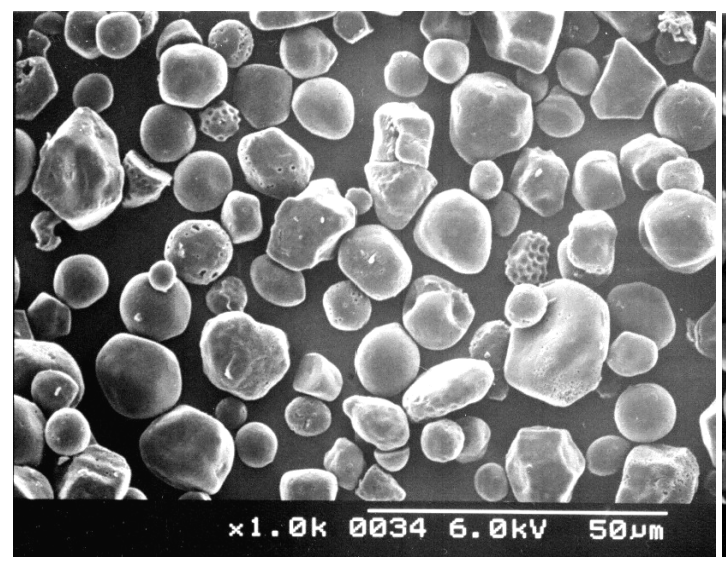

(a)

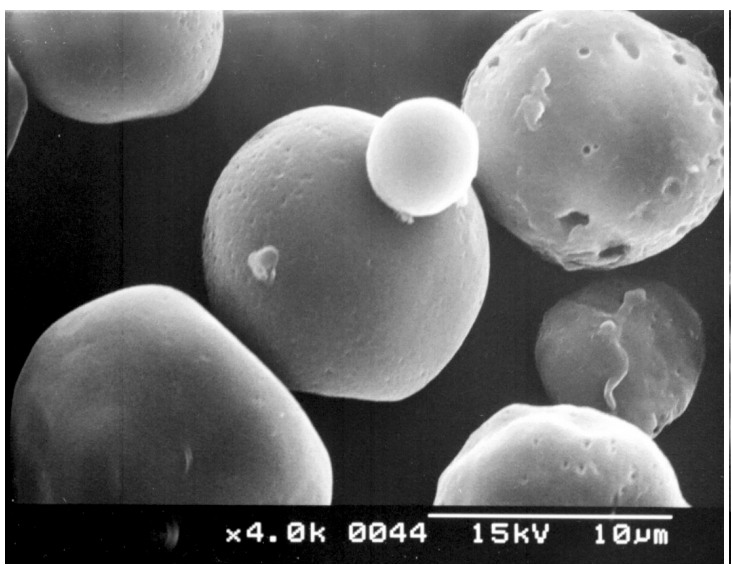

(c)

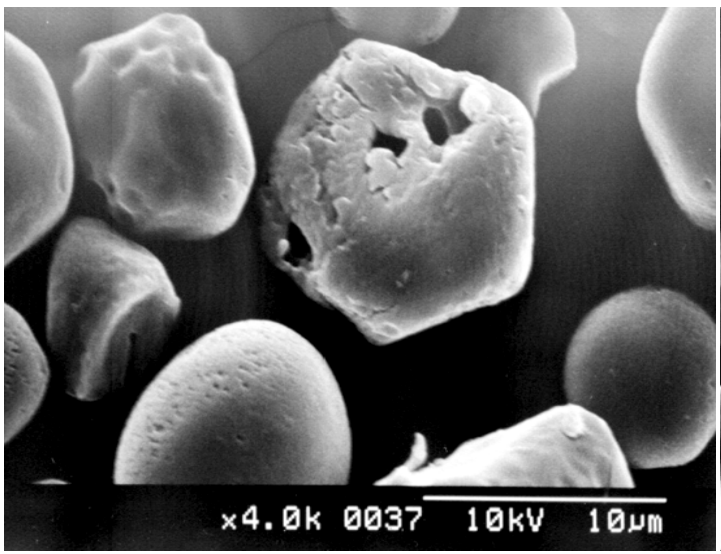

(e)

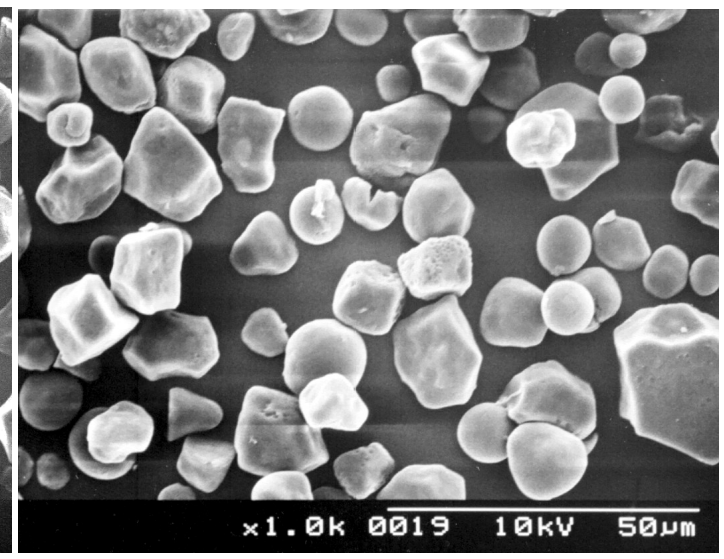

(b)

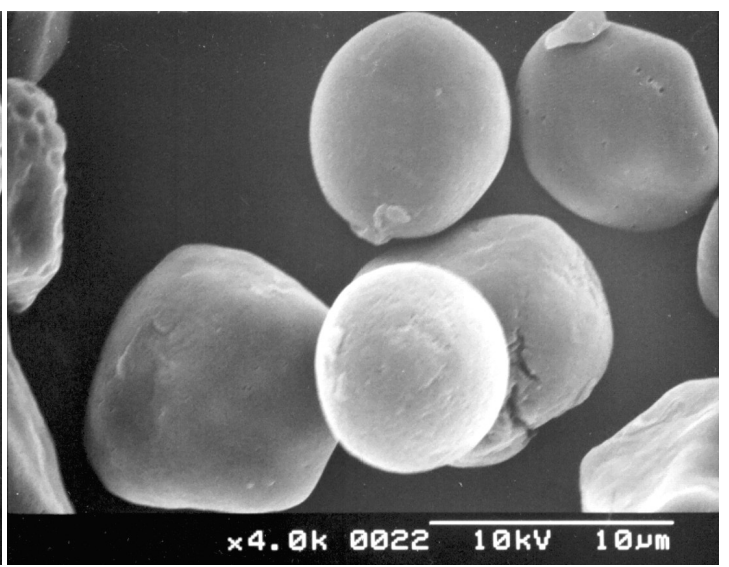

(d)

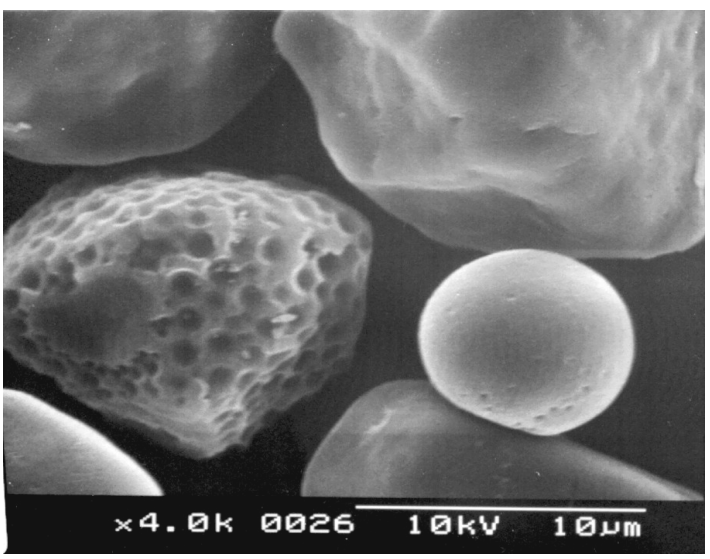

(f)

Figure 1. SEM micrographs of Florencia (a, c, e) and waxy maize starches (b, d, f).

Due to their elastic compression behaviour, starches can not be tabletted without auxiliary materials. As given in part 2.8, the powder mixture used for compression data analysis contained $20 \%$ starch, $78 \%$ microcrystalline cellulose as binder and $1 \%$ magnesium stearate as lubricant, respectively. When starches are utilized as disintegrants, they are in generally used in this concentration [37].

According to the results of the compression data analysis summarized in Table 3, a high input energy ( $\left.E_{\text {input }}\right)$ was required for the compression and a considerable part of this energy was lost by die-wall and interparticle friction as indicated by the friction work (FW) and the lubrication index (R). There was no considerable dif- 


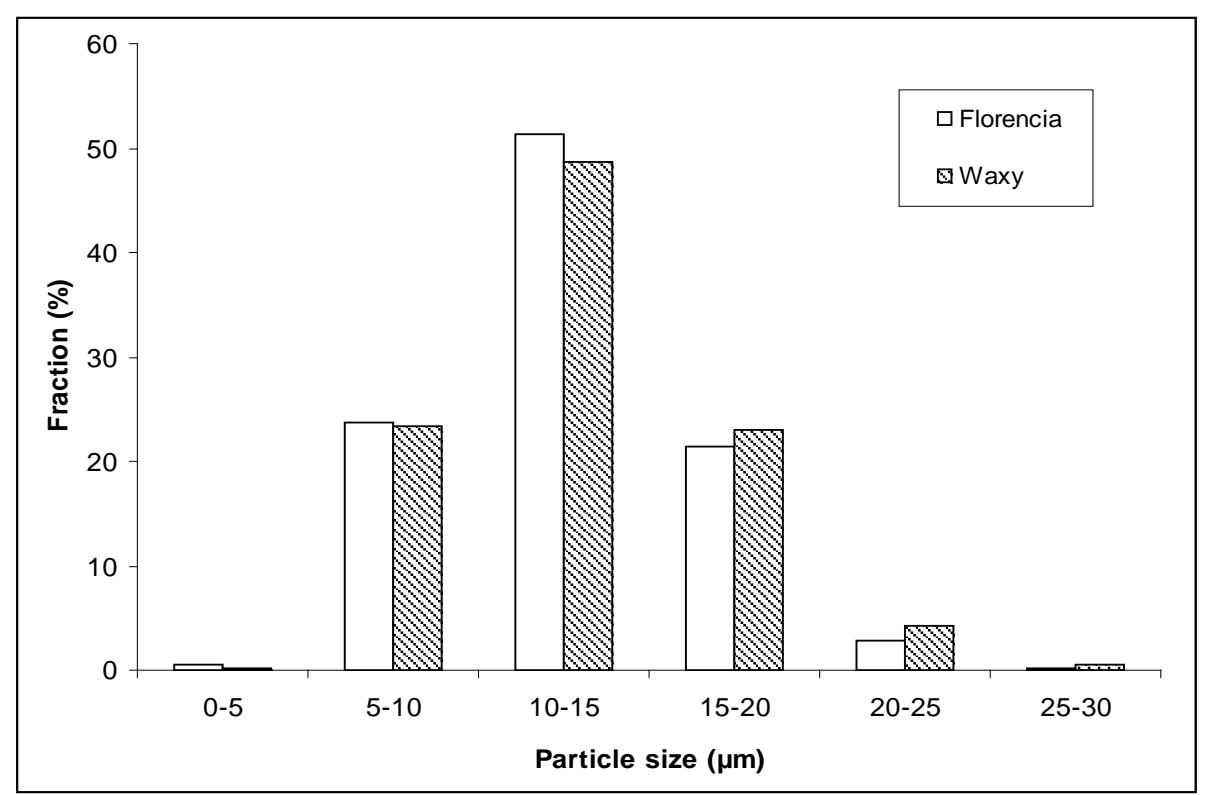

Figure 2. Particle size distribution of the starch samples.

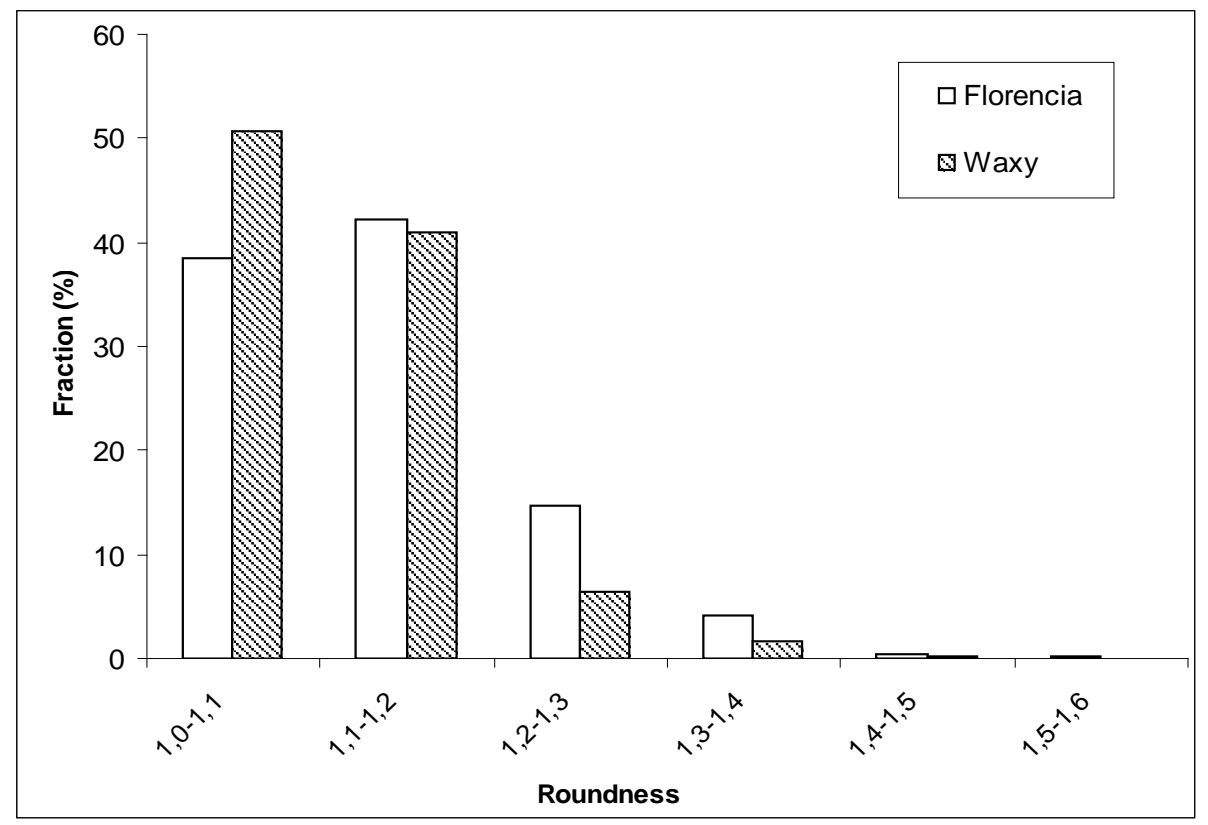

Figure 3. Particle roundness of the samples.

ference between the characteristics of the samples concerning the effective work $\left(E_{2}\right)$, the deformation characteristics $\left(\mathrm{Pl}_{\mathrm{S}-\mathrm{M}}, \mathrm{Pl}_{\mathrm{E}}\right)$, the energy of friction and the lubrication coefficients $(\mathrm{R})$. Nevertheless, the elastic recovery of the comprimates after ejection (ER) and the values of compressibility $\left(\operatorname{Pr}_{\text {(mass) }}\right)$ display better compression properties for the Florencia type.

Tableting experiments provide valuable information for the optimization of tablet composition about material properties, equipment characteristics and the impact of environmental factors. In these experiments, tablets containing calcium hydrogenphosphate dihydrate (Parmcompress ${ }^{\circledR}$ ) or microcrystalline cellulose (Avicel PH $101^{\circledR}$ ) as solid binders were compressed by using three different compression forces (5, 10 and $20 \mathrm{kN}$ ). Parmcompress $^{\circledR}$ and Avicel PH $101^{\circledR}$ are frequently used excipients in tablet formulation because their application allows the direct compression of powder blends containing considerable amounts of substances with poor flow- 


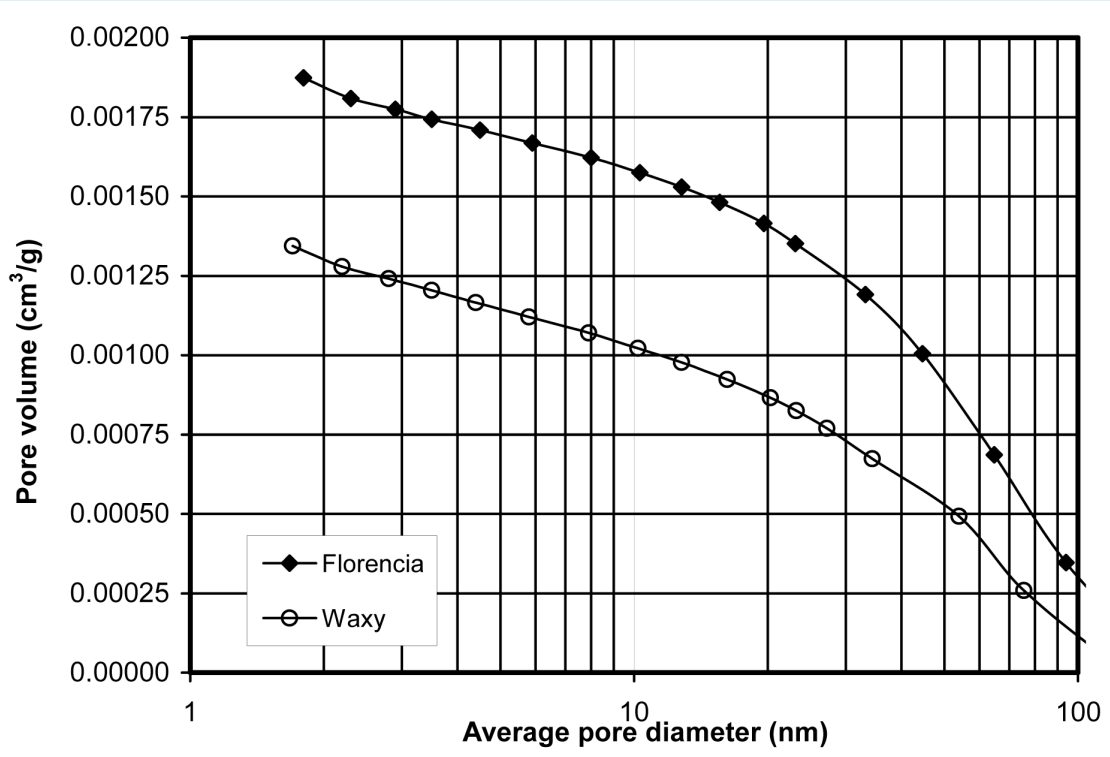

Figure 4. Pore volume-size distribution of Florencia and waxy maize starches.
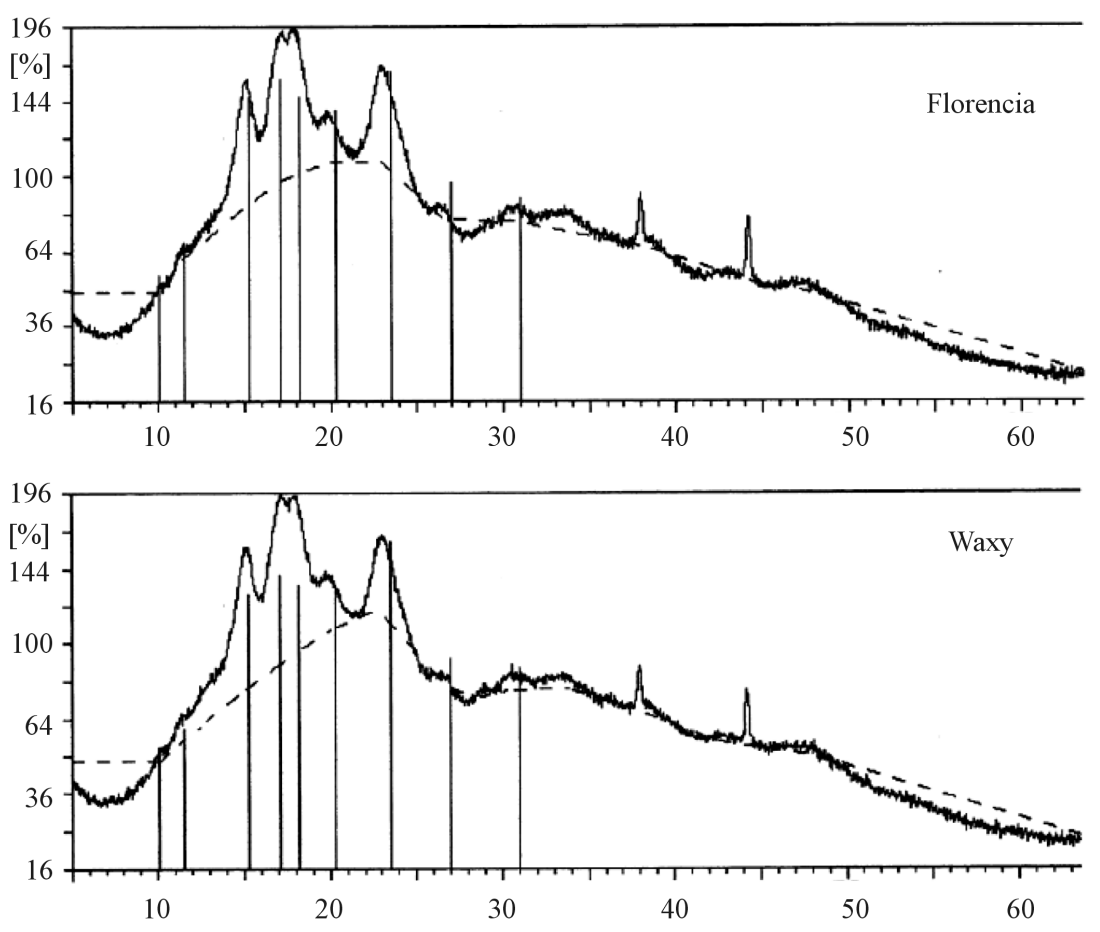

Figure 5. X-ray diffraction curves of the samples.

ability and compressibility [38] [39], which can be also confirmed with the negligible elastic recovery of the compacts (Table 3). The geometrical parameters and two functional tablet properties (crushing strength and disintegration time) were examined in this study.

The evaluation of mechanical strength and disintegration time of the tablets produced by using Parmcompress $^{\circledR}$ as a solid filler-binder did not provide adequate results (experimental data are not presented here). The tablets disintegrated immediately on contact with water. This phenomenon can be attributed to the elastic compression behaviour of starches. In addition, the poor deformation properties of the binding agent may also have an impact on the examined tablet parameters.

The results obtained for the tablets containing microcrystalline cellulose as binder are included in Table 4. It 
Table 1. Physical parameters of the starch samples (SD).

\begin{tabular}{ccc}
\hline Parameter & Florencia & Waxy \\
\hline Moisture content $(\%)$ & $8.07(0.07)$ & $7.30(0.15)$ \\
$\mathrm{F}_{\mathrm{BET}}\left(\mathrm{m}^{2} / \mathrm{g}\right)$ & 0.46 & 0.45 \\
$\mathrm{~V}\left(\mathrm{~cm}^{3} / \mathrm{g} * 10^{4}\right)$ & 18.74 & 13.49 \\
$\mathrm{D}(\mathrm{nm})$ & 14.9 & 10.8 \\
\hline
\end{tabular}

Table 2. Parameters of powder rheological investigation of Florencia and waxy maize starch (SD).

\begin{tabular}{ccc}
\hline Parameter & Florencia & Waxy \\
\hline Flow time $(\mathrm{s} / 100 \mathrm{ml})$ & no free flow & no free flow \\
Angle of repose $\left({ }^{\circ}\right)$ & $29.94(1.18)$ & $51.73(1.26)$ \\
Bulk density $(\mathrm{g} / \mathrm{ml})$ & $0.65(0.01)$ & $0.55(0.02)$ \\
True density $(\mathrm{g} / \mathrm{ml})$ & $3.05(0.36)$ & $2.56(0.15)$ \\
Carr index $(\%)$ & $26.4(0.97)$ & $28.96(1.32)$ \\
\hline
\end{tabular}

Table 3. Compression parameters of the tablets containing Florencia and waxy maize starch (SD).

\begin{tabular}{ccc}
\hline Parameter & Florencia & Waxy \\
\hline Upper punch displacement $(\mathrm{mm})$ & $7.80(0.02)$ & $8.47(0.03)$ \\
Upper punch compression force $(\mathrm{kN})$ & $4.69(0.11)$ & $4.78(0.36)$ \\
Lower punch compression force $(\mathrm{kN})$ & $3.08(0.08)$ & $3.16(0.24)$ \\
$\mathrm{E}_{\text {input }}(\mathrm{J})$ & $11.18(0.45)$ & $12.43(0.83)$ \\
$\mathrm{E}_{1}(\mathrm{~J})$ & $4.90(0.60)$ & $5.29(1.16)$ \\
$\mathrm{E}_{2}(\mathrm{~J})$ & $6.98(0.29)$ & $7.14(0.51)$ \\
$\mathrm{E}_{3}(\mathrm{~J})$ & $1.27(0.08)$ & $1.22(0.31)$ \\
$\mathrm{FW}_{(\mathrm{J})}$ & $0.35(0.02)$ & $0.35(0.03)$ \\
$\mathrm{Pl}_{\mathrm{S}-\mathrm{M}}(\%)$ & $84.61(0.03)$ & $85.53(2.78)$ \\
$\mathrm{Pl}_{\mathrm{E}}$ & $0.52(0.01)$ & $0.52(0.01)$ \\
$\operatorname{Pr}_{(\text {mass }}$ & $64.2(2.7)$ & $60.3(3.9)$ \\
$\mathrm{R}$ & $0.66(0.01)$ & $0.66(0.01)$ \\
$\mathrm{ER}(\%)$ & 0.03 & 0.12 \\
\hline
\end{tabular}

Table 4. Geometrical parameters and functional properties of tablets containing microcrystalline cellulose (Avicel PH 101®) (SD).

\begin{tabular}{ccccccc}
\hline & \multicolumn{3}{c}{ Florencia } & & Waxy & \\
\hline Compaction pressure (kN) & $\mathbf{5}$ & $\mathbf{1 0}$ & $\mathbf{1 5}$ & $\mathbf{5}$ & $\mathbf{1 0}$ & $\mathbf{1 5}$ \\
\hline Mass (g) & $0.2979(0.002)$ & $0.2972(0.003)$ & $0.2917(0.003)$ & $0.2755(0.010)$ & $0.2733(0.011)$ & $0.2808(0.008)$ \\
Height (mm) & $3.33(0.006)$ & $3.02(0.071)$ & $2.74(0.026)$ & $3.126(0.042)$ & $2.780(0.081)$ & $2.669(0.052)$ \\
Diameter (mm) & $10.04(0.005)$ & $10.03(0.007)$ & $10.01(0.002)$ & $10.04(0.007)$ & $10.03(0.006)$ & $10.02(0.005)$ \\
Crushing strength (N) & $77.3(4.99)$ & $122.0(6.12)$ & $165.0(5.96)$ & $66.8(8.59)$ & $104.5(12.02)$ & $153.2(9.96)$ \\
Disint. time (s) & 10 & 12 & 19 & 9 & 13 & 13 \\
\hline
\end{tabular}


Table 5. Swelling characteristics of the tablets containing Parmcompress (SD).

\begin{tabular}{ccc}
\hline Parameter & Florencia & Waxy \\
\hline Swelling force (N) & $17.64(2.67)$ & $15.78(2.11)$ \\
Characteristic swelling time (s) & $38.48(11.75)$ & $64.89(18.54)$ \\
\hline
\end{tabular}

is noteworthy, that the standard deviation of the parameters obtained for the Florencia starch is notably lower compared to the waxy mutant. This is especially revealed for the strength parameters. The crushing strength of the tablets containing the sample extracted from the Florencia genotype was significantly higher than that of the tablets compressed from waxy maize starch. These results can be related to the better flowability of Florencia starch. A good flowability permits rapid and uniform die filling resulting in better mechanical properties of the comprimates. The higher moisture content of Florencia starch might also have an advantageous influence on the strength parameters, since water acts as an internal lubricant (plasticizer) in starches and facilitates their consolidation during the tableting process.

The study of swelling characteristics was carried out by using the tablets containing Parmcompress ${ }^{\circledR}$ as filler compressed at $20 \mathrm{kN}$, since calcium hydrogenphosphate dihydrate does not swell in water and allows the accurate characterization of the swelling process.

According to the results included in Table 5, the tablets containing waxy maize starch indicate smaller swelling force and a significantly longer swelling process $(\mathrm{p}<0.05)$. Due to its fast and pronounced swelling mechanism, the Florencia starch can be regarded more effective when used as disintegrant.

\section{Conclusions}

As compared to waxy maize starch, the Florencia type exhibited identical structure and similar particle characteristics (particle size, shape and micromorphology). Furthermore, maize starch extracted from the Florencia dent hybrid showed better flowability and compressibility in tableting experiments, which resulted in better mechanical tablet properties.

With regard to utilization as a disintegrant, Florencia starch indicated rapid and intensive swelling and proved to act more effectively in the swelling process than waxy maize starch.

These results allow the conclusion that Florencia starch has a great potential for the application as an excipient in tablet formulations.

\section{References}

[1] Parker, R. and Ring, S.G. (2001) Aspects of the Physical Chemistry of Starch. Journal of Cereal Science, 34, 1-17. http://dx.doi.org/10.1006/jcrs.2000.0402

[2] Ellis, R.P., Cochrane, M.P., Dale, M.F.B., Duffus, C.M., Lynn, A., Morrison, I.M., Prentice, R.D.M., Swanston, J.S. and Tiller, S.A. (1998) Starch Production and Industrial Use. Journal of the Science of Food and Agriculture, 77, 289311. http://dx.doi.org/10.1002/(SICI)1097-0010(199807)77:3<289::AID-JSFA38>3.0.CO;2-D

[3] Puchongkavarin, H., Bergthaller, W., Shobsngob, S. and Varavinit, S. (2003) Characterization and Utilization of AcidModified Rice Starches for Use in Pharmaceutical Tablet Compression. Starch/Stärke, 55, 464-475. http://dx.doi.org/10.1002/star.200300232

[4] Zobel, H.F. (1988) Molecules and Granules: A Comprehensive Starch Review. Starch/Stärke, 40, 44-50. http://dx.doi.org/10.1002/star.19880400203

[5] Takeda, Y., Shitaozono, T. and Hizukuri, S. (1988) Molecular Structure of Corn Starch. Starch/Stärke, 40, 51-54. http://dx.doi.org/10.1002/star.19880400204

[6] Buléon, A., Colonna, P., Planchot, V. and Ball, S. (1998) Starch Granules: Structure and Biosynthesis. International Journal of Biological Macromolecules, 23, 85-112. http://dx.doi.org/10.1016/S0141-8130(98)00040-3

[7] Tamaki, S., Hisamatsu, M., Teraishi, K., Adachi, T. and Yamada, T. (1998) Structural Change of Maize Starch Granules by Ball-Mill Treatment. Starch/Stärke, 50, 342-348. http://dx.doi.org/10.1111/j.1440-1746.1998.tb00672.x

[8] Cheetham, N.W.H. and Tao, L. (1998) Variation in Crystalline Type with Amylose Content in Maize Starch Granules: An X-Ray Powder Diffraction Study. Carbohydrate Polymers, 36, 277-284.

http://dx.doi.org/10.1016/S0144-8617(98)00007-1 
[9] Van Soest, J.J.G., De Wit, D. and Vliegenthart, J.F.G. (1996) Mechanical Properties of Thermoplastic Waxy Maize Starch. Journal of Applied Polymer Science, 61, 1927-1937.

http://dx.doi.org/10.1002/(SICI)1097-4628(19960912)61:11<1927::AID-APP7>3.0.CO;2-L

[10] Willett, J.L., Millard, M.M. and Jasberg, B.K. (1997) Extrusion of Waxy Maize Starch: Melt Rheology and Molecular Weight Degradation of Amylopectin. Polymer, 38, 5983-5989. http://dx.doi.org/10.1016/S0032-3861(97)00155-9

[11] Riley, C.K., Adebayo, S.A., Wheatley, A.O. and Asemota, H.N. (2006) Fundamental and Derived Properties of Yam (Dioscorea Spp.) Starch Powders and Implications in Tablet and Capsule Formulation. Starch/Stärke, 58, 418-424. http://dx.doi.org/10.1002/star.200600491

[12] Rahmouni, M., Lenaerts, V., Massuelle, D., Doelker, E. and Leroux, J.-C. (2002) Influence of Physical Parameters and Lubricants on the Compaction Properties of Granulated and Non-Granulated Cross-Linked High Amylose Starch. Chemical and Pharmaceutical Bulletin, 50, 1155-1162. http://dx.doi.org/10.1248/cpb.50.1155

[13] Atichokudomchai, N., Shobsngob, S., Chinachoti, P. and Varavinit, S. (2001) A Study of Some Physicochemical Properties of High-Crystalline Tapioca Starch. Starch/Stärke, 53, 577-581. http://dx.doi.org/10.1002/1521-379X(200111)53:11<577::AID-STAR577>3.0.CO;2-0

[14] Szepes, A., Hasznos-Nezdei, M., Kovács, J., Funke, Z., Ulrich, J. and Szabó-Révész, P. (2005) Microwave Processing of Natural Biopolymers-Studies on the Properties of Different Starches. International Journal of Pharmaceutics, 302, 166-171. http://dx.doi.org/10.1016/j.ijpharm.2005.06.018

[15] Szepes, A., Mohnicke, M. and Szabó-Révész, P. (2007) Water Sorption Behavior and Swelling Characteristics of Starches Subjected to Dielectric Heating. Pharmaceutical Development and Technology, 12, 555-561. http://dx.doi.org/10.1080/10837450701558079

[16] Szepes, A., Makai, Zs., Blümer, C., Mäder, K., Kása Jr., P. and Szabó-Révész, P. (2008) Characterization and Drug Delivery Behaviour of Starch-Based Hydrogels Prepared via Isostatic Ultrahigh Pressure. Carbohydrate Polymers, 72, 571-578. http://dx.doi.org/10.1016/j.carbpol.2007.09.028

[17] Park, I.-M., Ibanez, A.M., Zhong, F. and Shoemaker, C.F. (2007) Gelatinization and Pasting Properties of Waxy and Non-Waxy Rice Starches. Starch/Stärke, 59, 388-396. http://dx.doi.org/10.1002/star.200600570

[18] Yoon, H.-S., Kweon, D.-K. and Lim, S.-T. (2007) Effects of Drying Process for Amorphous Waxy Maize Starch on Theophylline Release from Starch-Based Tablets. Journal of Applied Polymer Science, 105, 1908-1913. http://dx.doi.org/10.1002/app.26239

[19] Callens, C., Adriaens, E., Dierckens, K. and Remon, J.P. (2001) Toxicological Evaluation of a Bioadhesive Nasal Powder Containing a Starch and Carbopol ${ }^{\circledR} 974$ P on Rabbit Nasal Mucosa and Slug Mucosa. Journal of Controlled Release, 76, 81-91. http://dx.doi.org/10.1016/S0168-3659(01)00419-9

[20] Ceulemans, J., Vermeire, A., Adriaens, E., Remon, J.P. and Ludwig, A. (2001) Evaluation of a Mucoadhesive Tablet for Ocular Use. Journal of Controlled Release, 7, 333-344. http://dx.doi.org/10.1016/S0168-3659(01)00522-3

[21] Ferrari, F., Rossi, S., Martini, A., Muggetti, L., De Ponti, R. and Caramella, C. (1997) Technological Induction of Mucoadhesive Properties on Waxy Starches by Grinding. European Journal of Pharmaceutical Sciences, 5, 277-285. http://dx.doi.org/10.1016/S0928-0987(97)00018-3

[22] Voća, N., Krička, T., Janušić, V. and Matin, A. (2007) Bioethanol Production from Corn Kernel Grown with Different Cropping Intensities. Cereal Research Communications, 35, 1309-1312.

[23] Pap, R., Neményi, M. and Kovács A.J. (2004) Examination of Starch of Different Corn Hybrids Extracted by Wet Milling Procedure, and Their Evaluation According to Their Appropriateness for Biopolymer Production. Presentation at ASAE/CSAE Annual International Meeting, Ottawa, Ontario, Canada,

[24] Szabó-Révész, P., Hasznos-Nezdei, M., Farkas, B., Göcző, H., Pintye-Hódi, K. and Erős, I. (2002) Crystal Growth of Drug Materials by Spherical Crystallization. Journal of Crystal Growth, 237-239, 2240-2245. http://dx.doi.org/10.1016/S0022-0248(01)02237-0

[25] Brunauer, S., Emmett, P.H. and Teller, E. (1938) Adsorption of Gases in Multimolecular Layers. Journal of American Chemical Society, 60, 309-319. http://dx.doi.org/10.1021/ja01269a023

[26] Barrett, E.P., Joyner, L.G. and Halenda, P.P. (1951) The Determination of Pore Volume and Area Distributions in Porous Substances. I. Computations from Nitrogen Isotherms. Journal of American Chemical Society, 73, 373-380. http://dx.doi.org/10.1021/ja01145a126

[27] Tüske, Zs., Regdon Jr., G., Erős, I., Srčič, S. and Pintye-Hódi, K. (2005) The Role of the Surface Free Energy in the Selection of a Suitable Excipient in the Course of a Wet-Granulation Method. Powder Technology, 155, 139-144. http://dx.doi.org/10.1016/j.powtec.2005.05.058

[28] Carr, R.L. (1965) Evaluating Flow Properties of Solids. Chemical Engineering, 72, 69. 
[29] Wells, J.I. (1988) Pharmaceutical Preformulation. In: Rubinstein, M.M., Ed., Physicochemical Properties of Drug Substances, Ellis Horwood Limited, Chinchester, UK, 209-214.

[30] Stamm, A. and Mathis, C. (1976) Verpressbarkeit von Festen Hilfsstoffen für Direkttablettierung. Acta Pharmaceutica Technologica, Suppl. 1, 7-16.

[31] Bajdik, J., Pintye-Hódi, K., Novák, Cs., Kelemen, A., Regdon Jr., G. and Erős, I. (2002) Indirect Methods for Determination of the Protective Effects of Coating Films on the Surface of crystals. Journal of Thermal Analysis and Camlorimetry, 68, 1572-8943. http://dx.doi.org/10.1023/A:1016060323790

[32] Emschermann, B. and Müller, F. (1981) Auswertung der Kraftmessung beim Tablettieren. Pharmazeutische Industrie, 43, 191-194.

[33] Siaan, M., Pintye-Hódi, K., Szabó-Révész, P., Kása Jr., P. and Erős, I. (2000) Influence of Avicel PH-301 on the Compressibility of $\alpha$-Methyldopa and Phenobarbitone in Direct Compression. Drug Development and Industrial Pharmacy, 26, 1013-1018. http://dx.doi.org/10.1081/DDC-100101331

[34] Armstrong, N.A. and Haines-Nutt, R.F. (1974) Elastic Recovery and Surface Area Changes in Compacted Powder Systems. Powder Technology, 9, 287-290. http://dx.doi.org/10.1016/0032-5910(74)80054-9

[35] Hódi, K., Révész, P. and Miseta, M. (1992) Measurement of the Swelling Pressure and Its Significance in Producing Tablets. Gyógyszerészet, 36, 623-627.

[36] Langenbucher, F. (1972) Linearization of Dissolution Rate Curves by Weibull Distribution. Journal of Pharmacy and Pharmacology, 24, 979-981. http://dx.doi.org/10.1111/j.2042-7158.1972.tb08930.x

[37] Bos, C.E., Bolhuis, G.K., van Doorne, H. and Lerk, C.F. (1987) Native Starch in Tablet Formulations: Properties on Compaction. Pharmaceutisch Weekblad Scientific Edition, 9, 274-282. http://dx.doi.org/10.1007/BF01953630

[38] Szabó-Révész, P., Pintye-Hódi, K., Miseta, M. and Selmeczi, B. (1988) Microcrystal Cellulose Prepared Tablets Examination Part l: The Desintegration and Increase Hardness Effect of Avicel PH 101. Pharmazeutische Industrie, 50, 981-983.

[39] Podczeck, F. and Révész, P. (1993) Evaluation of the Properties of Microcrystalline and Microfine Cellulose Powders. International Journal of Pharmaceutics, 91, 183-193. http://dx.doi.org/10.1016/0378-5173(93)90338-G 